Jurnal SEOI - Fakultas Teknik Universitas Sahid Jakarta

Vol 2 edisi 1 tahun 2020

\title{
PENDEKATAN METODE AHP DALAM PENENTUAN SUPPLIER BAHAN BAKU TEPUNG DI PT MOLEK MANIS MERAUKE
}

\section{AHP METHOD APPROACH IN SUPPLIER DETERMINATION FLOUR RAW MATERIALS IN PT MOLEK MANIS MERAUKE}

\author{
Yunita Nema Savitri ${ }^{1}$, Dino Rimantho ${ }^{2}$ \\ Program studi Teknik Industri, Universitas Pancasila, Jl. Srengseng Sawah, Jagakarsa, Jakarta Selatan 12640, \\ Indonesia, Email koresponden: dino.rimantho@univpancasila.ac.id
}

\begin{abstract}
ABSTRAK
Terdapat beberapa faktor yang menentukan produk roti yang berkualitas. Salah satu faktor tersebut adalah pemilihan supplier bahan baku yang tepat, sehingga hal ini menuntut perusahaan untuk melakukan pemilihan supplier secara tepat dan efisien. Penelitian ini menggunakan dua buah kuesioner yang didistribusikan kepada 9 orang responden untuk kuesioner 1 dan 3 orang reponden untuk kuesioner 2. Penelitian ini dilakukan pada PT Molek Manis Merauke dengan meggunakan metode Analytic Hiererchy Process (AHP). Hasil yang diperoleh pada penelitian ini adalah untuk kriteria kapasitas produksi bobot nilai sebesar $(0,50)$, kualitas produk $(0,31)$, harga $(0,12)$, dan waktu $(0,04 \%)$. Pada kriteria kapasitas produksi terdapat dua sub kriteria yaitu ketersediaan bahan baku dengan bobot $(0,65)$, dan kuantitas supplier $(0,56)$. Untuk kriteria kualitas produk sub kriteria yaitu ketahanan bahan baku $(0,50)$, dan kualitas bahan baku yang di tawarkan $(0,46)$. Untuk kriteria harga terdapat dua sub kriteria yaitu ketentuan pembayaran $(0,39)$, dan harga yang seuai $(0,25)$. Dan untuk kriteria waktu memiliki dua sub kriteria yaitu ketersediaan SDM $(0,22)$, dan waktu ketersediaan barang $(0,19)$. Dari hasil perhitungan, terpilih supplier A yaitu Toko Bintoro sebagai supplier dengan bobot nilai terbesar $(0,579)$ dari supplier $B$ yaitu Agen Samira dengan bobot $(0,216)$, supplier $C$ yaitu Agen Alian (0,251), dan supplier D yaitu Toko Mitra Sawang dengan bobot nilai sebesar $(0,442)$.
\end{abstract}

Kata Kunci: AHP, Bahan Baku, Pemilihan, Roti, Supplier

\begin{abstract}
There are several factors that determine the quality of bread products. One of the factor is the selection of appropriate raw material suppliers, thus it requires the company to perfom supplier selection correctly and efficiently. This study used two questionnaires that distributed to 9 respondents for questionnaire 1 and 3 respondents for questionnaire 2. This research was arrange at PT Molek Manis Merauke by using the metod Analytic Hiererchy Process (AHP). Results in this study is to criteria production capacity weights value of $(0,50)$, product quality $(0,31)$, the price of $(0,12)$, and time $(0,04)$. To a criterion production capacity there are two sub criteria the availability of raw materials with weights $(0,65)$, and quantity of supplier $(0,56)$. To criteria product quality criteria security sub the raw materials $(0,50)$, and quality of raw materials offer $(0,46)$. For the price of criteria there are two sub criteria that is a payment term $(0,39)$, and suitable prices $(0,25)$. And to criteria time having two sub criteria the availability of human resources $(0,22)$, and the availability of goods $(0,19)$. From the calculation, elected Supplier A the "Toko Bintoro" as supplier with weights the greatest value $(0,579)$ of supplier B the "Agen Samira" with weights $(0,216)$, suppliers $C$ the "Agen Alian" (0,251), and suppliers D the "Toko Mitra Sawang" with weights value of $(0,442)$.
\end{abstract}

Keywords: AHP, Raw Material, Choice, Bread, Supplier 
Jurnal SEOI - Fakultas Teknik Universitas Sahid Jakarta

Vol 2 edisi 1 tahun 2020

\section{Pendahuluan}

Di tengah maraknya perkembangan bisnis roti di Indonesia, tentu para pelaku bisnis membutuhkan kreativitas untuk merebut pasar. Dalam perkembangan itu sendiri terdapat beraneka ragam yakni mulai dari segi rasa, bentuk, harga dan yang terpenting adalah kualitas roti itu sendiri. Mengacu pada tingkat terpenting dalam menghasilkan sebuah produk makanan seperti roti yaitu kualitas produk yang dihasilkan haruslah baik dan terjamin. Untuk menghasilkan produk makanan dengan kualitas yang baik tentu membutuhkan bahan-bahan dengan kualitas yang juga baik terutama bahan baku. Pemilihan bahan baku yang berkualitas dan sesuai dengan standar yang ditentukan merupakan suatu yang harus dilakukan, ini tentunya akan memberikan sebuah peluang pasar yang sangat baik, hal ini juga melibatkan para parusahaan penyedia bahan baku tersebut atau supplier. Namun pada umumnya tidak semua supplier menyediakan bahan dengan kualitas yang bagus, untuk itu para pelaku bisnis roti harus dapat memutuskan atau memilih supplier dengan benar dan cermat.

Para pelaku bisnis roti pada saat ini telah banyak melakukan inovasi baik dalam segi pemasaran maupun produk. Tentu saja inovasi ini dimaksudkan untuk menarik minat konsumen terhadap produk roti dan meningkatkan kualitas pasar. Perusahaan Roti "Molek Manis" Merauke merupakan pelaku bisnis roti yang sedang berkembang di daerah Merauke. Namun perusahaan tersebut bukan satu-satunya perusahaan roti yang ada di daerah Merauke, perusahaan Molek Manis ini memiliki beberapa pesaing dibidang yang sama. Perusahaan ini memiliki dua jenis produk yakni roti tawar dan roti manis. Pada dasarnya produk roti yang di produksi oleh Perusahaan Molek Manis ini telah di kenal hampir seluruh masyarakat daerah Merauke. Berdasarkan penelitian yang telah dilakukan, produk roti Molek Manis yang paling diminati oleh masyarakat yaitu roti tawar.

Pemilihan supplier ini akan melalui beberapa proses yang cukup panjang, yang tentunya perlu adanya proses penawaran, pemesanan, waktu dan lain-lain. Kualitas tepung yang ditawarkan oleh supplier tentunya berbeda-beda, hal ini di karenakan tepung juga memiliki tingkat ketahanan atau keawetan yang berbeda. Oleh karena hal itu, maka pihak perusahaan mengalami kesulitan dalam menentukan supplier. Pemilihan supplier yang tepat sangat perlu dilakukan untuk mendapatkan kriteria supplier yang betul-betul mampu untuk memenuhi kebutuhan bahan baku perusahaan secara konsisten dan berkualitas. Langkah awal yang dapat dilakukan yaitu menyeleksi supplier yang berkompeten dan berkualitas.

Pembenahan ataupun perbaikan terhadap manajemen rantai pasokan sangatlah diperlukan karena dapat menjadi salah satu alternatif strategi yang bisa digunakan oleh perusahaan. Dalam merancang sistem rantai pasokan, ada beberapa hal yang perlu dipertimbangkan dalam memilih pemasok, diantaranya kualitas barang yang ditawarkan, harga barang, dan ketetapan waktu pengiriman (Pujawan, 2005).

Berdasarkan studi pendahuluan yang dilakukan diperoleh informasi bahwa terdapat beberapa supplier yang diajukan oleh PT Molek Manis Merauke. Adapun supplier tersebut antara lain, Supplier A, Supplier B, Supplier C, dan Supplier D. Para supplier tersebut merupakan supplier lokal dari Indonesia yang akan menyediakan bahan-bahan baku yang dibutuhkan oleh perusahaan dalam proses produksi roti. Selain itu, para supplier tersebut juga memiliki keunggulan dan kelemahan masing-masing. Sehingga, pihak PT Molek Manis Merauke yang melakukan pengambilan keputusan harus memilih supplier dengan baik dan dapat menyediakan keperluan yang diperlukan oleh PT Molek Manis Merauke. Dengan memilih supplier yang terbaik tentu dapat mengurangi terjadinya risiko keterlambatan dalam proses produksi dan kerugian finansial.

Terdapat beberapa metode yang dapat digunakan dalam pengambilan keputusan, metode yang umum digunakan oleh para pengambil kebijakan, misalnya TOPSIS, ANP, dan AHP. 
Jurnal SEOI - Fakultas Teknik Universitas Sahid Jakarta

Vol 2 edisi 1 tahun 2020

Metode-metode tersebut telah banyak diaplikasikan dalam berbagai kegiatan misalnya, metode AHP yang telah banyak digunakan oleh para peneliti dalam pengelolaan limbah elektronika (Rimantho dkk., 2015) dan keputusan pemilihan vendor dalam proyek konstruksi (Giantoro, 2015). Lebih lanjut, metode AHP dapat digunakan untuk menentukan bobot multi kriteria yang selanjutnya dapat juga digabungkan dengan model lainnya (Yuen 2009). Metode ini telah banyak diaplikasikan dalam berbagai permasalahan, seperti pembangunan perumahan berkelanjutan (Pattinaja and D. Rimantho, 2017); pemilihan supplier (Rimantho et al., 2017). prioritas proposal penelitian (dos Santos Oliveira et al., 2013), pemilihan proyek (Pangsri, 2015]. Berdasarkan uraian yang telah dijelaskan sebelumnya, maka pada penelitian ini bertujuan untuk menganalisis Penentuan Supplier Bahan Baku Tepung dengan Penerapan AHP Pada PT Molek Manis Merauke".

\section{Metode}

Jenis data yang dikumpulkan meliputi data primer dan data sekunder. Data primer merupakan data yang didapat dari sumber pertama baik dari individu seperti pengamatan langsung ke lokasi penelitian, wawancara dengan pihak yang terkait dengan rencana penelitian. Selain itu, data primer juga diperoleh melalui pengisisan kuesioner yang terdiri dari dua kuesioner. Kuesioner pertama menanyakan tentang deskripsi kriteria, sub kriteria, dan alternatif terkait pemilihan supplier pada PT Molek Manis Merauke. Kuesioner kedua adalah kuesioner bobot kriteria dan sub kriteria, dan bobot alternatif supplier. Data sekunder merupakan data yang telah diolah dan biasanya disajikan dalam bentuk tabel-tabel dan diagram-diagram. Data sekunder diperoleh melalui perusahaan dan literatur yang relevan dengan topik penelitian.

Ada beberapa jenis cara pengambilan sampel dengan teknik ini, namun untuk penelitian ini digunakan cara keputusan atau judgement sampling karena peneliti memilih anggota-anggota sampel untuk menyesuaikan diri dengan beberapa kriteria yang dibutuhkan dalam penelitian ini. Kuesioner pertama, untuk mengetahui faktor-faktor yang digunakan oleh PT. Molek Manis Merauke dalam pengambilan keputusan pemilihan supplier. Faktor-faktor ini meliputi kriteria, sub kriteria dan alternatifnya. Adapun jumlah responden yang digunakan pada kuesioner pertama ini sekitar sembilan. Pertanyaan yang terdapat pada kuesioner ini selanjutnya divalidasi guna mengetahui kevalidan dari kuesioner tersebut.

Kuesioner kedua, respondennya terdiri dari pihak-pihak yang diasumsikan mengetahui dan memiliki pengalaman dalam hal pemilihan supplier bahan baku pada PT Molek Manis Merauke. Kuesioner kedua ini merupakan perbandingan secara berpasangan dari kriteria, sub kriteria dan alternatif. Responden dipilih berdasarkan beberapa pertimbangan, diantaranya paling mengetahui tentang kondisi supplier perusahaan dan menjadi pengambil keputusan dalam memilih supplier perusahaan. Adapun jumlah responden yang digunakan pada kuesioner yang kedua sekitar tiga orang

Pengolahan data yang dilakukan adalah dimulai dari data yang diperoleh di lapangan kemudian dilakukan perhitungan dengan menggunakan metode AHP (Analytic Hierarchy Process). Metode analisis data yang digunakan dalam penelitian ini adalah analisis kualitatif dan analisis kuantitatif. Analisis kualitatif digunakan untuk memperoleh gambaran kondisi rantai pasokan perusahaan, supplier material, kriteria, dan sub kriteria yang digunakan untuk memilih supplier bahan baku tepung bagi perusahaan. Sedangkan analisis kuantitatif dilakukan dengan menggunakan metode Analytic Hierarchy Process (AHP).

Tujuan penerapan metode AHP dalam penelitian ini adalah untuk menemukan kriteria dan sub kriteria pemasok yang terbaik, yaitu kriteria dan sub kriteria supplier yang memiliki rata-rata 
skor paling tinggi dengan mempertimbangkan tingkat kepentingan kriteria dan sub kriteria yang dianggap mempengaruhi keputusan.

Dalam metode AHP, proses untuk mendapatkan skor tersebut diawali dengan perbandingan berpasangan (pairwise comparison) antar kriteria dan antar sub kriteria yang nantinya akan digunakan untuk mendapatkan tingkat kepentingan relatif tiap kriteria (criteria weight) dan sub kriteria (sub criteria weight). Selanjutnya dilakukan perbandingan berpasangan antar alternatif keputusan pada masing-masing faktor untuk mendapatkan kepentingan relatif antar alternatif pada setiap sub kriteria (sub criteria evaluation). Bila hasil perhitungan konsistensi lebih dari 0,1 maka harus dilakukan perhitungan ulang, sedangkan bila hasil perhitungan konsistensi kurang dari 0,1 maka alternatif dapat dipilih.

\section{Hasil dan Pembahasan}

Data perbandingan berpasangan yang didapat melalui kuesioner dari tiga orang responden, kemudian dicari salah satu nilai untuk satu matriks perbandingan, menggunakan perataan jawaban atau geometric mean. Berikut adalah hasil penilaian perbandingan berpasangan oleh para responden pada kriteria.

Tabel 1 Hasil perbandingan berpasangan pada kriteria

\begin{tabular}{llll}
\hline \multirow{2}{*}{\multicolumn{1}{c}{ Kriteria }} & \multicolumn{3}{c}{ Responden } \\
\cline { 2 - 4 } & 1 & 2 & 3 \\
\hline Kapasitas Produksi - Kualitas Produk & 1 & 3 & 5 \\
Kapasitas Produksi - Harga & 7 & 9 & 5 \\
Kapasitas Produksi - Waktu & 7 & 9 & 5 \\
Kualitas Produk - Harga & 9 & 5 & 5 \\
Kualitas Produk - Waktu & 9 & 5 & 7 \\
Harga - Waktu & 9 & 5 & 7 \\
\hline
\end{tabular}

Selanjutnya dibuat matriks penilaian perbandingan berpasangan antar kriteria terhadap pemilihan supplier bahan baku tepung. Kriteria yang dibandingan secara berpasangan adalah kapasitas produksi, kualiras produk, harga, dan waktu. Maktriksnya dapat dilihat pada tabel berikut ini:

Tabel 2 Matriks Perbandingan Berpasangan Antar Kriteria

\begin{tabular}{lcccc}
\hline Kriteria & $\begin{array}{c}\text { Kapasitas } \\
\text { Prduksi }\end{array}$ & $\begin{array}{c}\text { Kualitas } \\
\text { Produk }\end{array}$ & Harga & Waktu \\
\hline Kapasitas & 1 & 2,47 & 6,8 & 6,8 \\
Produksi & 0,41 & 1 & 6,12 & 6,8 \\
Kualitas Produk & 0,15 & 0,16 & 1 & 6,8 \\
Harga & 0,15 & 0,15 & 0,15 & 1 \\
Waktu & 1,71 & 3,78 & 14,07 & 21,4 \\
\hline \multicolumn{1}{c}{ Jumlah } & & & & \\
\hline
\end{tabular}

Dari matriks yang telah dinormalkan dapat dihitung nilai rata-rata (X bobot) dari setiap baris dan matriks seperti tabel berikut: 
Jurnal SEOI - Fakultas Teknik Universitas Sahid Jakarta

Vol 2 edisi 1 tahun 2020

Tabel 3 Normalisasi Bobot Perbandingan Berpasangan Antar Kriteria

\begin{tabular}{lcccccc}
\hline Kriteria & $\begin{array}{c}\text { Kapasitas } \\
\text { Prduksi }\end{array}$ & $\begin{array}{c}\text { Kualitas } \\
\text { Produk }\end{array}$ & Harga & Waktu & $\sum$ & $\begin{array}{c}\text { X } \\
\text { Bobot }\end{array}$ \\
\hline Kapasitas & 0,58 & 0,65 & 0,48 & 0,31 & 2,03 & 0,50 \\
Produksi & 0,23 & 0,26 & 0,43 & 0,31 & 1,25 & 0,31 \\
Kualitas Produk & 0,08 & 0,04 & 0,07 & 0,31 & 0,51 & 0,12 \\
Harga & 0,08 & 0,03 & 0,01 & 0,04 & 0,18 & 0,04 \\
Waktu & 1 & 1 & 1 & 1 & & 1 \\
\hline \multicolumn{1}{c}{ Jumlah } & & & & & & \\
\hline
\end{tabular}

Selanjutnya dilakukan analisis penilaian perbandingan berpasangan antar sub kriteria pada kriteria kapasitas produksi terhadap pemilihan supplier bahan baku tepung. Sub kriteria yang dibandingan secara berpasangan adalah ketersediaan bahan baku dan kuantitas supplier. Maktriksnya dapat dilihat pada tabel berikut ini:

Tabel 4 Perbandingan berpasangan antar subkriteria

\begin{tabular}{lcc}
\hline Kapasitas Produksi & $\begin{array}{c}\text { Ketersediaan Bahan } \\
\text { Baku }\end{array}$ & Kuantitas Supplier \\
\hline Ketersediaan Bahan Baku & 1 & 6,80 \\
Kuantitas Supplier & 0,15 & 1 \\
Kualitas Produk & Ketahanan Bahan Baku & Kualitas Bahan Baku yang \\
Ketahanan Bahan Baku & 1 & Ditawarkan \\
Kualitas Bahan Baku yang & 0,13 & 7,61 \\
Ditawarkan & Ketentuan Pembayaran & 1 \\
Harga & 1 & Harga Yang Sesuai \\
Ketentuan Pembayaran & 0,15 & 6,80 \\
Harga Yang Sesuai & Ketersediaan SDM & 1 \\
Waktu & 1 & Waktu Ketersediaan Barang \\
Ketersediaan SDM & 0,18 & 5,63 \\
Waktu Ketersediaan Barang & & 1 \\
\hline
\end{tabular}

Kemudian dilakukan pengujian Consistency Ratio (CR) setiap matriks perbandingan berpasangan, kemudian dilakukan pengujian Consistency Ratio of Hierarchy (CRH). Prinsipnya adalah dengan mengkalikan semua nilai Consistency Index (CI) dengan bobot suatu kriteria yang menjadi acuan pada suatu matriks perbandingan berpasangan dan kemudian menjumlahkannya. Jumlah tersebut dibandingkan dengan nilai yang didapat dengan cara sama tetapi untuk suatu matriks random (RI). Hasil akhirnya berupa suatu parameter yang disebut dengan Consistency Ratio of Hierarchy (CRH). Suatu hirarki disebut konsisten bila nilai CRH tidak lebih dari 0,10 $(\mathrm{CRH} \leq 0,10)$. 
Jurnal SEOI - Fakultas Teknik Universitas Sahid Jakarta

Vol 2 edisi 1 tahun 2020

Hasil Perhitungan Consistency Index of Hierarchy $(\mathrm{CIH})$ seperti pada tabel berikut:

Tabel 5 Consistency Index of Hierarchy $(\mathrm{CIH})$

\begin{tabular}{lccc}
\hline \multicolumn{1}{c}{ Kriteria } & X Bobot & CI & CIH \\
\hline Kapasitas Produksi & 0,50 & 0,02 & 0,01 \\
Kualitas Produk & 0,31 & 0,09 & 0,0279 \\
Harga & 0,12 & 0,01 & 0,0012 \\
Waktu & 0,04 & 0,01 & 0,0004 \\
\hline \multicolumn{7}{c}{ Total } & & 0,0395 \\
\hline
\end{tabular}

Untuk perhitungan Random Index of Hierarchy (RIH). Seperti pada tabel berikut ini:

Tabel 6 Random Index of Hierarchy (RIH)

\begin{tabular}{lccc}
\hline \multicolumn{1}{c}{ Kriteria } & X Bobot & RI & RIH \\
\hline Kapasitas & & & \\
Produksi & 0,50 & 0,9 & 0,45 \\
Kualitas Produk & 0,31 & 0,9 & 0,279 \\
Harga & 0,12 & 0,9 & 0,108 \\
Waktu & 0,04 & 0,9 & 0,036 \\
\hline \multicolumn{4}{c}{ Total } \\
\hline
\end{tabular}

Setelah didapat $\mathrm{CIH}$ dan RIH maka dapat diketahui Consistency Ratio of Hierarchy (CRH) perhitungannya seperti pada persamaan berikut:

$$
\mathrm{CRH}=\frac{\mathrm{CIH}}{\mathrm{RIH}}=\frac{0,0395}{0,873}=0,04524
$$

Nilai Consistency Ratio of Hierarchy $(C R H)$ sebesar 0,04524 lebih kecil dari 0,1, maka dapat dikatakan bahwa hirarki yang dibuat telah konsisten karena sesuai dengan syarat yang di kemukakan Saaty.

Setelah data yang diperoleh telah dinyatakan konsisten, maka dapat ditentukan urutan alternatif sesuai dengan bobot prioritas. Bobot prioritas didapat dari perkalian antara masingmasing bobot kriteria dengan bobot sub kriteria, sehingga didapat bobot global yang digunakan untuk menentukan urutan prioritas.

Dari nilai bobot hasil perhitungan kriteria kapasitas produksi menjadi kriteria utama dalam pemilihan supplier bahan baku tepung, dengan sub kriteria Ketersediaan bahan baku. Sedangkan kriteria kualitas produk menduduki urutan prioritas kedua dalam pemilihan supplier bahan baku tepung, dengan sub kriteria ketahanan bahan baku. Kemudian urutan ketiga adalah kriteria harga, dengan sub kriteria ketentuan pembayaran. 
Jurnal SEOI - Fakultas Teknik Universitas Sahid Jakarta

Vol 2 edisi 1 tahun 2020

Tabel 7 Urutan Prioritas Kriteria

\begin{tabular}{|c|c|c|c|c|c|}
\hline Kriteria & $\begin{array}{c}\text { Bobot } \\
\text { Kriteria } \\
\end{array}$ & Sub Kriteria & $\begin{array}{c}\text { Bobot Sub } \\
\text { Kriteria }\end{array}$ & $\begin{array}{l}\text { Bobot } \\
\text { Global }\end{array}$ & $\begin{array}{c}\text { Urutan } \\
\text { Prioritas } \\
\end{array}$ \\
\hline \multirow{2}{*}{$\begin{array}{l}\text { Kapasitas } \\
\text { Produksi }\end{array}$} & \multirow{2}{*}{0,50} & Ketersediaan bahan baku & 0,65 & 0,325 & 1 \\
\hline & & Kuantitas Supplier & 0,56 & 0,280 & 2 \\
\hline \multirow{2}{*}{$\begin{array}{l}\text { Kualitas } \\
\text { Produk }\end{array}$} & \multirow[b]{2}{*}{0,31} & Ketahanan bahan baku & 0,50 & 0,155 & 3 \\
\hline & & $\begin{array}{l}\text { Kualitas bahan baku yang } \\
\text { ditawarkan }\end{array}$ & 0,46 & 0,142 & 4 \\
\hline \multirow{2}{*}{ Harga } & \multirow{2}{*}{0,12} & Ketentuan pembayaran & 0,39 & 0,046 & 5 \\
\hline & & Harga yang sesuai & 0,25 & 0,030 & 6 \\
\hline \multirow{2}{*}{ Waktu } & \multirow{2}{*}{0,04} & Ketersediaan SDM & 0,22 & 0,008 & 7 \\
\hline & & Waktu ketersediaan barang & 0,19 & 0,007 & 8 \\
\hline
\end{tabular}

Ketersediaan bahan baku menjadi prioritas utama dalam pengambilan keputusan pemilihan supplier, hal ini didasarkan pada realita bahwa posisi/lokasi perusahaan yang berada di Merauke, sedangkan pengiriman bahan baku oleh supplier dilakukan dari pulau Jawa yaitu Surabaya.

Pengiriman bahan baku yang dilakukan dengan menggunakan kapal laut ini tentunya juga mempengaruhi kuantitas supplier dalam memenuhi permintaan perusahaan, dikarenakan waktu yang diperlukan cukup lama yakni satu bulan. Kuantitas supplier menentukan jumlah produk yang dapat diproduksi oleh perusahaan.

Berdasarkan penelitian/studi yang dilakukan, bahwa harga bahan baku yang ditawarkan tentunya berkaitan dengan ketersediaan bahan baku. Hal ini dikarenakan pengiriman bahan baku yang dilakukan dari Surabayadengan menggunakan kapal laut tentunya memerlukan biaya/ongkos kirim.

Tahap terakhir adalah menghitung bobot prioritas pemilihan alternatif supplier, yang juga dihitung bobot supplier dan bobot globalnya, yang merupakan perkalian antara bobot supplier dengan bobot yang ada di level atasnya. Hasil rekapitulasi bobot supplierr dan bobot global bisa dilihat pada tabel berikut.

Tabel 8 Bobot Alternatif Supplier

\begin{tabular}{lccccc}
\hline \multirow{2}{*}{ Sub Kriteria } & & \multicolumn{4}{c}{ Bobot Supplier } \\
\cline { 3 - 6 } & Bobot Global & Supplier & Supplier & Supplier & Supplier \\
& & A & $B$ & $C$ & $D$ \\
\hline Ketersediaan bahan baku & 0,325 & 0,64 & 0,23 & 0,34 & 0,17 \\
Kuantitas Supplier & 0,280 & 0,55 & 0,27 & 0,14 & 0,78 \\
Ketahanan bahan baku & 0,155 & 0,69 & 0,17 & 0,21 & 0,57 \\
Kualitas bahan baku yang & 0,142 & 0,45 & 0,12 & 0,32 & 0,40 \\
ditawarkan & 0,046 & 0,42 & 0,31 & 0,26 & 0,22 \\
Ketentuan pembayaran & 0,030 & 0,40 & 0,13 & 0,32 & 0,36 \\
Harga yang sesuai & 0,008 & 0,37 & 0,24 & 0,20 & 0,28 \\
Ketersediaan SDM & 0,007 & 0,40 & 0,31 & 0,07 & 0,06 \\
Waktu ketersediaan barang & & & & & \\
\hline
\end{tabular}


Jurnal SEOI - Fakultas Teknik Universitas Sahid Jakarta

Vol 2 edisi 1 tahun 2020

Tabel 9 Bobot Global Supplier

\begin{tabular}{lccccc}
\hline \multirow{2}{*}{\multicolumn{1}{c}{ Sub Kriteria }} & \multirow{4}{c}{ Bobot Global } & Supplier & Supplier & Supplier & Supplier \\
& & A & $B$ & $C$ & $D$ \\
\hline Ketersediaan bahan baku & 0,325 & 0,21 & 0,07 & 0,11 & 0,05 \\
Kuantitas Supplier & 0,28 & 0,15 & 0,07 & 0,034 & 0,22 \\
Ketahanan bahan baku & 0,155 & 0,11 & 0,03 & 0,03 & 0,09 \\
Kualitas bahan baku yang & 0,142 & 0,06 & 0,02 & 0,05 & 0,06 \\
ditawarkan & 0,046 & 0,02 & 0,01 & 0,01 & 0,01 \\
Ketentuan pembayaran & 0,03 & 0,01 & 0,004 & 0,015 & 0,01 \\
Harga yang sesuai & 0,008 & 0,002 & 0,002 & 0,002 & 0,002 \\
Ketersediaan SDM & 0,007 & 0,002 & 0,002 & 0,0005 & 0,0004 \\
Waktu ketersediaan barang & & 0,579 & 0,216 & 0,2513 & 0,4424 \\
\hline
\end{tabular}

Secara global prioritas pertama untuk pemilihan supplier bahan baku tepung adalah Supplier A (Toko Bintoro) dengan bobot 0,579 . Hal ini juga di dukung oleh lokasi toko yang berada di daerah Merauke, dan merupakan salah satu supplier terbesar yang ada di daerah tersebut. Mengingat ketersediaan bahan baku menjadi faktor yang utama dalam pemilihan supplier ini maka hal tersebut tentunya sangat mendukung untuk memenuhi kebutuhan bahan baku yang dibutuhkan oleh perusahaan.

\section{Kesimpulan}

Berdasarkan hasil penelitian dan pembahasan yang telah dilakukan, maka diperoleh kesimpulan bahwa dari perkembangan hirarki yang dilakukan, meghasilkan suatu model hirarki dengan tiga tingkatan hirarki. Tingkatan pertama (level 1) terdapat kriteria-kriteria yang digunakan dalam pemilihan supplier yaitu, kriteria kapasitas produksi, kriteria kualitas produk, kriteria harga, dan kriteria waktu. Dan pada kriteria-kriteria tersebut terdapat sub kriteria yang berada pada hirarki tingkatan kedua (level 2), pada hirarki tingkatan ketiga (level 3) adalah alternatif dari tujuan yaitu supplier-supplier bahan baku tepung. Hasil dari penelitian yang dilakukan dengan menggunakan metode AHP menunjukkan bahwa supplier bahan baku tepung yang dipilih adalah Supplier A "Toko Bintoro" dengan bobot 0,579. Saran yang dapat diberikan dari hasil penelitian pada PT Molek Manis Merauke adalah perusahaan pada umumnya dapat menggunakan metode atau pendekatan AHP sebagai alternatif dalam melakukan pemilihan dan mecari solusi dari permasalahan yang dihadapi. Berdasarkan hasil pembobotan yang telah diperoleh pada metode ini, selain digunakan untuk pemilihan supplier juga dapat digunakan untuk menilai kinerja pada supplier yang bekerja sama dengan perusahaan. Sebaiknya kriteria-kriteria dan sub kriteria yang digunakan lebih spesifik lagi agar hasil yang diperoleh lebih akurat.Apabila dilakukan penelitian lebih lanjut sebaiknya dapat membandingakan metode yang digunakan saat ini oleh penulis dengan metode-metode AHP lainnya, misalnya Fuzzy AHP. 
Jurnal SEOI - Fakultas Teknik Universitas Sahid Jakarta

Vol 2 edisi 1 tahun 2020

\section{Daftar Pustaka}

Pattinaja, A., \& Rimantho, D. (2017). Strategy of the policy of sustainable housing development using AHP method at the village Ihamahu-Maluku, Indonesia. International Journal of Applied Engineering Research, Vol. 12, (pp. 4238-4247).

Rimantho, D., Fathurohman, F., Cahyadi, B., \& Sodikun, S. (2017). Pemilihan Supplier Rubber Parts Dengan Metode Analytical Hierarchy Process Di PT. XYZ. Jurnal Rekayasa Sistem Industri, vol. 6, 93-104.

Rimantho, D., Rahman, T. A., \& Cahyadi, B. (2017). Application of six sigma and AHP in analysis of variable lead time calibration process instrumentation. in AIP Conference Proceedings 1813, 040004. doi:/10.1063/1.4975969

Dos Santos Oliveira, D. R. M., de Alencar Nääs, I., \& Barros, F. M. M. (2013). Prioritization of Research Proposals Using the Analytic Hierarchy Process-AHP. in IFIP International Conference on Advances in Production Management Systems (pp. 347-352). PA, USA: State College.

Giantoro. (2015). Analisa Keputusan Pemilihan Vendor Dalam Proyek Konstruksi.

Yuen, K. K. F., (2009). On Limitations of the Prioritization Methods in Analytic Hierarchy Process: A Study of Transportation Selection Problems. in Proceedings of the International MultiConference of Engineers and Computer Scientists. Hongkong.

Pujawan, Nyoman, I. (2005). Supply Chain Management. Surabaya : Guna widya.

Rimantho, D., Cahyadi, B, Dermawan, D. (2015). Application Analytic Hierarchy Process (AHP): A case study of e-waste management in Surabaya, Indonesia. In Industrial Engineering and Management (8th ISIEM), Malang, Indonesia. 